\title{
Marital Distress, Depression, and Attributions: Is the Marital Distress-Attribution Association an Artifact of Depression?
}

\author{
Frank D. Fincham \\ University of Illinois at Urbana-Champaign
}

\author{
Steven R. H. Beach \\ University of Georgia
}

\author{
Thomas N. Bradbury \\ University of Illinois at Urbana-Champaign
}

\begin{abstract}
We examined whether the association between marital distress and attributions is an artifact of depression. Study 1 showed that the attributions of 40 wives recruited from the community accounted for variance in their marital satisfaction after the effects of depression had been taken into account. Study 2 compared the attributions of 20 clinically depressed and maritally distressed wives (respondents to an advertisement offering therapy for depression and marital problems), 20 nondepressed but distressed wives (clients seeking marital therapy at a clinic), and a control group of 20 nondepressed and nondistressed wives (respondents to an advertisement for participants in a research project). The first two groups did not differ in attributions, but the attributions of both groups differed from those of the control group. Both studies therefore suggest that the association between attributions and marital satisfaction is not due to depression.
\end{abstract}

Compared with happily married spouses, distressed spouses tend to make attributions that accentuate the impact of negative marital events and minimize the impact of positive marital events (see Bradbury \& Fincham, in press). Despite its implications for clinical practice, little research exists concerning why there is an association between attributions and marital satisfaction, and no effort has been made to investigate rival explanations for this association. This is a serious omission because the associations found between depression and attributions (see Robins, 1988) and between depression and marital distress (see Beach, Sandeen, \& O'Leary, in press) suggest that the relation between attributions and marital satisfaction may reflect their joint association with depression. We therefore examined whether spouses' level of depression might account for the attribution-satisfaction relation.

It is important to investigate whether depression gives rise to the association between attributions and satisfaction for both theoretical and practical reasons. At the theoretical level, it is necessary to determine whether the findings obtained for spouses' attributions constitute a marital phenomenon per se. To the extent that such findings simply reflect spousal depression, the centrality of attributions in emerging accounts of marital dysfunction would be called into question. At the applied level, if some patterns of attribution are associated only with marital discord, then there is no reason to expect that interven-

Preparation of this article was supported by Grants MH44078-01, MH42085-01, and MH 09740-01 from the National Institute of Mental Health awarded to Frank D. Fincham, Steven R. H. Beach, and Thomas N. Bradbury, respectively.

Correspondence concerning this article and requests for an extended report of these studies should be addressed to Frank D. Fincham, Psychology Department, University of Illinois, 603 East Daniel Street, Champaign, Illinois 61820 . tions designed to alleviate a spouse's depression will change attributions that influence his or her marital satisfaction. Conversely, if marital attributions are part of a more general pattern of attributions resulting from depression, attempts to change attributions that focus solely on the marriage would be less than optimal.

\section{Study 1}

This study examined the relation between responsibility attributions, marital satisfaction, and depressive symptoms in a sample of community wives. Responsibility attributions concern who is held accountable, whereas causal attributions determine who or what produced an event. Because responsibility attributions may be more strongly related to marital satisfaction than causal attributions (Fincham \& Bradbury, in press), they were investigated in this study. Only wives participated in the study because the higher incidence of depression among women increased the possibility of obtaining substantial variance in depressive symptoms and because no sex differences have been found in research on responsibility attributions and concurrent marital satisfaction.

\section{Method}

Forty married women were recruited by means of a newspaper advertisement that invited readers to participate in a survey on marriage. Respondents who were currently married, residing with their spouses, and not receiving any form of therapy were eligible for the study. All eligible respondents agreed to participate in the study. Participants averaged $35.0(S D=10.7)$ years of age, $13.4(S D=1.9)$ years of formal education, a gross family income of $\$ 30,000$ to $\$ 35,000,13.1(S D=$ $11.1)$ years of marriage, and $1.9(S D=1.2)$ children. The ethnic background of the sample was not known.

Marital satisfaction was measured by means of the Marital Adjustment Test (MAT; Locke \& Wallace, 1959). The mean MAT score was 
$104.7(S D=27.4)$ and thus fell just above the cutoff score of 100 that is typically used to separate distressed and nondistressed spouses. Depressive symptoms were assessed using the Beck Depression Inventory (BDI; Beck \& Beamesderfer, 1974). The mean BDI score, 9.7 ( $S D=$ 6.6), was just below the cutoff score of 10 on the BDI that is recommended to distinguish depression from nondepression.

Attributions were assessed for six hypothetical partner behaviors, including three positive behaviors ("Your spouse shows understanding for your feelings," "Your spouse responds positively to your suggestion to cuddle," "Your spouse treats you more lovingly") and three negative behaviors ("Your spouse does not pay attention to what you are saying," "Your spouse criticizes something you do," "Your spouse cuts down on the amount of time he/she spends with you in favor of an independent activity"). Hypothetical behaviors were used because the association between attributions and marital satisfaction does not vary as a function of the real versus hypothetical nature of stimuli (Fincham \& Beach, 1988), a high level of internal consistency is obtained when responses to both types of stimuli are combined (Fincham \& Bradbury, 1987), and the use of such stimuli facilitates comparison of responses across spouses. For each behavior, respondents made three responsibility attributions by indicating the extent to which the behavior was motivated by selfish concerns, was intentional, and was blameworthy/praiseworthy. All responses were made on 7-point scales. To enhance the reliability of the responsibility measures, two indices were formed by summing all nine responses to positive events and all nine responses to negative events (cf. Fincham \& Bradbury, 1987). Coefficient alpha for these indices was .78 and .74 , respectively.

Participants were mailed a packet of questionnaires consisting of the MAT, BDI, attribution measure, demographics questionnaire, and a self-addressed, postage-paid, return envelope. Participants were instructed to complete the questionnaires independently and at a single sitting as soon as possible after they had received them. A $\$ 10$ payment was made to each participant.

\section{Results and Discussion}

Consistent with prior research, marital satisfaction was related directly to seeing the causes of positive behaviors as intentional, unselfishly motivated, and praiseworthy, $r(40)=.67, p<$ .001 , and was related inversely to seeing the causes of negative behavior as intentional, selfishly motivated, and blameworthy, $r(40)=-.58, p<.001$. As anticipated, marital satisfaction was also inversely related to intensity of depressive symptoms, $r(40)=-.37, p<.05$.

To examine the extent to which depression might account for the association between attributions and marital satisfaction, a simultaneous multiple regression analysis was conducted in which the two attribution indices and BDI scores were used to predict marital satisfaction. The regression equation was significant, $R^{2}=.58, F(3,36)=14.20, p<.001$. More important, Table 1 shows that each attribution index accounted for unique variance in marital satisfaction. When considered together, the attribution indices accounted for $44 \%$ of the variance in satisfaction. Thus the relation between attributions and marital satisfaction remained significant even after the variance due to depression had been taken into account.

The associations between depression and marital satisfaction and between attributions and marital satisfaction were replicated in our study, yet no evidence was obtained to suggest that depression accounts for the relation between attributions and marital satisfaction. There are three reasons why it would be premature, however, to conclude that the findings obtained in
Table 1

Unique Variance in Marital Satisfaction

Associated With Predictor Variables

\begin{tabular}{lcc}
\hline Predictor variables & Study 1 & Study 2 \\
\hline Attribution indices & & \\
Positive behaviors & $16 \% * *$ & $4 \%^{*}$ \\
Negative behaviors & $9 \% *$ & $13 \%^{* * *}$ \\
BDI score & $3 \%$ & $36 \%^{* *}$ \\
\hline
\end{tabular}

Note. Unique variance represents the amount $R^{2}$ would drop if the predictor were omitted from the regression equation. BDI = Beck Depression Inventory.

${ }^{*} p<.05 . \quad{ }^{* *} p<.01$.

marital attribution research are not due to depression: The results may reflect restricted variation in BDI scores, the findings are limited by reliance on self-report of depressive symptoms, and the BDI measures the intensity of depressive symptoms rather than the clinical syndrome of depression.

\section{Study 2}

This study addressed the limitations of Study 1 by investigating wives who were diagnosed as clinically depressed. In order to test more completely the hypothesis that attributions for partner behavior vary as a function of marital satisfaction and not depression, three groups of wives were compared: a depressed and maritally distressed group (Group 1), a nondepressed but maritally distressed group (Group 2), and a group of wives who were neither depressed nor maritally distressed (Group 3). To the extent that depression accounts for marital attributions, it can be hypothesized that (a) Groups 1 and 2 will differ, (b) Groups 1 and 3 will differ, and (c) Groups 2 and 3 will not differ in attributions. In contrast, if marital distress influences attributions, it would be expected that (a) Groups 1 and 2 will not differ, (b) Groups 1 and 3 will differ, and (c) Groups 2 and 3 will differ in attributions.

\section{Method}

Participants were 60 White women (20 in each group) who were living with their husbands. Eighty-seven persons who responded to a newspaper advertisement offering therapy to women having problems with depression and with their marriage were screened in order to obtain 20 wives who met the criteria for the depressed and maritally distressed group. In order to be included in Group 1, women had to be depressed (obtain a BDI score of 14 or more and meet Diagnostic and Statistical Manual of Mental Disorders (DSM-III; American Psychiatric Association, 1980) criteria for a major depressive episode as assessed by a structured diagnostic interview and score in the distressed range $(<100)$ on the Dyadic Adjustment Scale (DAS; Spanier, 1976). Respondents were excluded if they met DSM-III criteria for substance dependence or had husbands who scored in the depressed range on the BDI. Of the 20 wives in this group, 6 were diagnosed as having dysthymia concurrent with the depressive episode. Mean duration of the presenting episode was 13.5 months (range of 1 to 30 months). The mean DAS and BDI scores for this group were $68.7(S D=19.6)$ and $28.1(S D=6.8)$, respectively. This group averaged 38.6 $(S D=6.0)$ years of age, $14.0(S D=2.8)$ years of education, $14.8(S D=8.5)$ years of marriage, a family income of $\$ 34,450(S D=\$ 16,210)$, and $2.1(S D 2.2)$ children. 
The nondepressed but maritally distressed group (Group 2) was selected from a pool of 58 couples seeking marital therapy. To be included, wives had to score in the maritally distressed range on the DAS $(<100)$ and in the nondepressed range on the BDI $(<14)$. This group had a mean DAS score of 79.6 $(S D=21.6)$ and a mean BDI score of $8.8(S D=$ 3.3). These wives averaged 35.2 $(S D=6.5)$ years of age, $14.8(S D=2.4)$ years of education, $9.8(S D=8.5)$ years of marriage, a family income of $\$ 39,670(S D=\$ 19,830)$, and $1.6(S D=1.3)$ children.

The community group (Group 3) was recruited by means of a newspaper advertisement, and 43 couples were screened. To be included in the study, wives had to score in the nondistressed range on the DAS and in the nondepressed range on the BDI. The mean DAS and BDI scores for this group were $118.2(S D=8.5)$ and $5.8(S D=3.5)$, respectively. This group averaged $37.5(S D=11.2)$ years of age, $13.9(S D=2.9)$ years of education, $13.6(S D=11.6)$ years of marriage, a family income of $\$ 35,350(S D=\$ 14,050)$, and $1.7(S D=1.7)$ children. A one-way multivariate analysis of variance (MANOVA) showed that the three groups did not differ from each other with regard to any of the demographic variables investigated, $F(8,110)=1.52, p=.2$.

As expected, the BDI scores for the three groups differed significantly, $F(2,59)=122.21, p<.001$. Regarding DAS scores, the maritally distressed and depressed group, $t(38)=10.84, p<.001$, and the maritally distressed and nondepressed group, $t(38)=8.14, p<.001$, differed from the community group. However, the two maritally distressed groups did not differ significantly from each other, $t(38)=-1.83, p>.10$.

The Structured Clinical Interview for DSM-III-Patient Version (SCID-P; Spitzer \& Williams, 1984) was used to make diagnoses. Interviewers were trained to a criterion of .90 reliability on symptom presence-absence decisions within each diagnostic category before participating as interviewers. Symptom ratings were reviewed by a second interviewer, and subjects received a consensus diagnosis before being included. No formal reliability analyses of the diagnoses were conducted. Attributions were assessed in the same manner as Study 1. Coefficient alpha for the positive (.74) and negative (.71) attribution indices again were satisfactory. Participants visited our research rooms for an assessment session as part of a larger project, at which time they independently completed the questionnaires.

\section{Results and Discussion}

A one-way MANOVA comparing the three groups on the two attribution indices yielded a significant effect, $F(4,98)=6.21$, $p<.001$. Table 2 shows that, for both positive and negative partner behavior, the attributions of wives who were maritally distressed and depressed did not differ from those of wives who were nondepressed but maritally distressed. Thus, regardless of their depression status, distressed wives made dysfunctional attributions for partner behavior. In contrast, the attributions of each of these groups differed significantly from those of nondepressed, happily married wives for three of the four comparisons; only the depressed, distressed group did not differ from the control group on the attribution index for negative partner behavior, although the means were in the predicted direction. These results are consistent with the view that marital distress, but not depression, accounts for the attribution differences obtained between groups.

To compare these findings with those obtained in Study 1, BDI scores and the two attribution indices were used to predict marital satisfaction. The overall regression equation was significant, $R^{2}=.65, F(3,50)=30.48, p<.001$. In contrast with Study 1, depression accounted for a significant portion of unique variance in satisfaction (see Table 1). This difference
Table 2

Means and Standard Deviations of Atribution Indices for Positive and Negative Partner Behavior (Study 2)

\begin{tabular}{lccc}
\hline & \multicolumn{3}{c}{ Group } \\
\cline { 2 - 4 } Behavior & $\begin{array}{c}\text { Distressed/ } \\
\text { depressed }\end{array}$ & $\begin{array}{c}\text { Distressed/ } \\
\text { nondepressed }\end{array}$ & $\begin{array}{c}\text { Nondistressed/ } \\
\text { nondepressed }\end{array}$ \\
\hline Positive & & & \\
$M$ & $21.9_{\mathrm{a}}$ & $23.4_{\mathrm{a}}$ & $14.9_{\mathrm{b}}$ \\
$S D$ & 7.8 & 6.4 & 5.2 \\
Negative & $39.7_{\mathrm{c}, \mathrm{d}}$ & $41.7_{\mathrm{c}}$ & $35.7_{\mathrm{d}}$ \\
$M$ & 8.4 & 6.7 & 9.3 \\
$S D$ &
\end{tabular}

Note. Means with the same subscripts do not differ significantly $(p<$ .05 ). For positive behaviors, higher scores indicate less intent, less positive motivation, and less praiseworthiness. For negative behaviors, higher scores indicate more intent, more selfish motivation, and more blameworthiness.

in findings most likely reflects greater variation in BDI scores caused by the inclusion of clinically depressed spouses in Study 2. More important, each attribution index accounted for unique variance in marital satisfaction. Together they accounted for $19 \%$ of the variance in marital satisfaction.

\section{General Discussion}

These studies are the first to rule out depression as an alternative explanation for the attribution-satisfaction relation that has been emphasized in the marital literature. The view that marital attribution research does indeed address a phenomenon specific to marriage, rather than depression, can therefore be held with greater confidence.

The finding in Study 2, that both attributions and depression account for unique variance in marital satisfaction, raises important theoretical questions. For example, one might ask whether attributions and depression are related causally to marital satisfaction. Similarly, it is important to ask whether the investigation of attributions in marriage can contribute to our understanding of the process leading to depression in married persons. It seems reasonable to argue that conflict-enhancing attributions are likely to influence spouse behavior, a position that has received some preliminary support (Bradbury \& Fincham, in press). Consistent use of such attributions is therefore likely to result in an increasingly stressful and nonsupportive environment and thereby may produce increased dysphoria and a greater likelihood of depression (see Beach, Sandeen, et al., in press). One means of investigating this possibility is to investigate whether interventions that change attributions of responsibility in marital relationships help prevent marital discord and depressive symptomatology.

Our findings also have important implications at the applied level. They replicate and extend earlier findings thus supporting the importance of addressing dysfunctional attributions, either directly or indirectly, in marital therapy. Perhaps the greatest value of addressing responsibility attributions may come early in therapy for couples who appear to be locked in a cycle of blame and counterblame (Beach \& Bauserman, in press). Alter- 
natively, it may prove useful to address responsibility attributions and other cognitions as they arise in the context of ongoing behavior change (Fincham \& Bradbury, in press). In either case, there is a need to develop empirically based cognitive interventions tailored to the marital context.

Finally, several limitations of the present studies affect the significance accorded their findings. First, only wives participated in the studies. Second, the results pertain only to responsibility attributions. Future research should include both causal and responsibility attributions. In view of these two considerations, the present results yield an incomplete picture of the role of attributions and depression in marriage. Third, the absence of a maritally nondistressed but depressed group in Study 2 did not allow us to examine whether depression and marital distress influence responsibility attributions similarly. Fourth, we were unable to investigate specific attribution dimensions. To the extent that hypotheses are specified for particular attribution dimensions, progress in research on marital attributions will be hindered by the lack of reliable measures of individual dimensions. Despite these limitations the present studies are important because they provide the first data on attributions and depression in marriage and do not support the hypothesis that the attribution-satisfaction association is an artifact of depression.

\section{References}

American Psychiatric Association. (1980). Diagnostic and statistical manual of mental disorders (3rd ed.). Washington, DC: Author.

Beach, S. R. H., \& Bauserman, S. A. (in press). Enhancing the effectiveness of marital therapy. In F. D. Fincham \& T. N. Bradbury (Eds.), The psychology of marriage: Basic issues and applications. New York: Guilford Press.
Beach, S. R. H., Sandeen, E., \& O'Leary, K. D. (in press). Depression in marriage: $A$ model for etiology and treatment. New York: Guilford Press.

Beck, A. T., \& Beamesderfer, A. (1974). Assessment of depression: The depression inventory. In P. Pichot (Ed.), Modern problems in pharmacopsychiatry (pp. 151-169). Basel, Switzerland: Karger.

Bradbury, T. N., \& Fincham, F. D. (in press). Attributions in marriage: Review and critique. Psychological Bulletin.

Fincham, F. D., \& Beach, S. R. (1988). Attribution processes in distressed and nondistressed couples: 5 . Real versus hypothetical events. Cognitive Therapy and Research, 12, 183-190.

Fincham, F. D., \& Bradbury, T. N. (1987). The impact of attributions in marriage: A longitudinal analysis. Journal of Personality and Social Psychology, 53, 510-517.

Fincham, F. D., \& Bradbury, T. N. (in press). Cognition in marriage: A program of research on attributions. In D. Perlman \& W. Jones (Eds.), Advances in Personal Relationships (Vol. 2). Greenwich, CT: JAI Press.

Locke, H. J., \& Wallace, K. M. (1959). Short marital-adjustment and prediction tests: Their reliability and validity. Marriage and Family Living, 21, 251-255.

Robins, C. J. (1988). Attributions and depression: Why is the literature so inconsistent? Journal of Personality and Social Psychology, 54, 880-889.

Spanier, G. B. (1976). Measuring dyadic adjustment: New scales for assessing the quality of marriage and similar dyads. Journal of Marriage and the Family, 38, 15-28.

Spitzer, R. L., \& Williams, J. B. W. (1984). Structured clinical interview for DSM-III. (Manual available from Biometrics Research Department, New York State Psychiatric Institute, 722 West 168th Street, New York, NY 10032.)

Received February 2, 1989

Revision received June 30, 1989

Accepted July 12, 1989

\section{Seeking New Clinical Research Methods: An Invitation to Contribute to a Special Series in the Journal of Consulting and Clinical Psychology}

Researchers are invited to contribute to a special series on new or refined methods and models useful to advance the theories and topics covered by the Journal. Papers on two kinds of topics are encouraged: (a) clinical research questions requiring innovative methods and (b) alternatives to traditional research design, sampling (e.g., randomization or matching), measurement, or analysis. Within the first area, authors should demonstrate that there are questions requiring rigorous procedures other than traditional research methods and models. These papers ought to be on the logic of the research question, with a two-part follow-up discussion: one describing why traditional methods are not adequate and the other describing the methods necessary and sufficient to address the question. Within the second area, authors can submit papers that cut across two or more issues (e.g., attrition). Editorial preference will be given to papers providing empirical verification of arguments made. The editors of this special series are Frederick L. Newman, University of Illinois at Chicago, and Kenneth I. Howard, Northwestern University. Authors should submit outlines of papers by March 1, 1990 to Frederick L. Newman, 1327 Lincoln Street, Evanston, Illinois 60201. 